\title{
Gagaku, de Olivier Messiaen
}

\author{
Luigi Antonio Irlandini (UDESC, Florianópolis, SC) \\ cosmofonia.lai@gmail.com; www.luigiantonioirlandini.org
}

Resumo: A tensão entre nostalgia e inovação se manifesta de maneira única em Gagaku, o quarto movimento de Sept Haikai, de Olivier Messiaen. A religiosidade de Messiaen representa uma forma de nostalgia para a vanguarda intelectual francesa. Messiaen considera o senso de ritual e de estase como expressões musicais do sagrado. Através da comparação da estrutura do Gagaku de Messiaen (analisado à luz de seus próprios escritos sobre os seus métodos composicionais) e da estrutura da música tradicional japonesa gagaku, este artigo mostra de que modo o senso de ritual e de estase constitui o elemento estético comum existente independentemente em ambas as formas musicais. A existência de um elemento comum entre a "fonte" não-ocidental e a composição ocidental inspirada por esta fonte provê a condição necessária para a transformação de nostalgia em inovação. 0 conceito de écriture tem um papel importante na dialética de passado/futuro desta transformação, causando estrutura e estilo a se diferenciarem baseados no princípio da nãoimitação, e afirmando-se como o elemento formativo que faz de Gagaku uma peça distintamente francesa.

Palavras-chave: Olivier Messiaen; vanguarda musical; influência não-ocidental; música japonesa tradicional; religião; estética musical.

\section{Messiaen's Gagaku}

Abstract: The tension between nostalgia and innovation is uniquely manifested in Olivier Messiaen's Gagaku, the fourth movement of his 1962 composition Sept Haikai. Messiaen's religiosity represented a form of nostalgia to the intellectual French Avant-Garde. Messiaen considers the sense of ritual and stasis as musical expressions of sacredness. By comparing the structure of Messiaen's Gagaku (analyzed in the light of his writings about his compositional methods) and that of ancient Japanese gagaku court music, this paper will show how this sense of ritual and stasis constitutes the aesthetic common ground existing independently in both forms. The existence of common elements between a non-western "source" and the western composition inspired by that source provides the necessary condition for the transformation of nostalgia into innovation. The concept of écriture plays an important role in the past/future dialectic of this transformation, causing structure and style to differ based on the principle of non-imitation and asserting itself as the shaping element that makes Gagaku a piece of distinctly French music.

Keywords: Olivier Messiaen; music avant-garde; non-western influence; traditional Japanese music; religion; musical aesthetics.

\section{1 - Messiaen e o Haiku japonês}

Gagaku é o movimento central de Sept Haikai, composto para orquestra por Olivier Messiaen (1908-1992) em 1962 após uma viagem de lua de mel e, ao mesmo tempo, tournée concertística, ao Japão. Messiaen falou em entrevistas sobre esta viagem e esta composição de um modo natural e despretensioso, que ligava a obra firmemente à sua vivência pessoal e turística. Ele viu no Japão um paraiso, "um país onde tudo é nobre" (SAMUEL, 1986). Sua fascinação pelo lugar, a cultura e o povo inspiraram-no a compor uma peça em sete movimentos curtos no espírito de ilustrações ou cartões postais. A evidência disto são os títulos de cada movimento, que são nomes de lugares que Messiaen visitou. Enquanto o primeiro e o último movimentos são intitulados, respectivamente Introduction e Coda, os outros tem os seguintes títulos: no.2: Le parc de Nara et les lanternes de pierre, no. 3: Yamanaka-Cadenza, no. 4: Gagaku, no. 5: Miyajima et le Torii dans la mer, no. 6: Les oiseaux de Karuizawa. Respectivamente, eles se referem ao parque de Nara com suas lanternas de pedra, ao lago Yamanaka, à execução ao vivo da música de corte gagaku, à ilha de Miyajima com seus pórticos no mar, e Karuizawa, um resort de montanha aos pés do vulcão Asama. 0 subtítulo "esquisses Japonaises" enfatiza a despretensiosa natureza de esboço da obra.

Devido ao termo haikai no título, o ouvinte se prepara para buscar elementos do haiku japonês tais como brevidade, surpresa, simplicidade, estrutura silábica, e uma ligação com a natureza. Em vez disto, o ouvinte se depara com algo bastante diferente. A duração dos haikai de Messiaen varia de um minuto e meio a cinco minutos e meio. Embora a sensação de tempo em 
música seja mais psicológica do que cronométrica, tais durações, prolongadas para um haiku e curtas para um compositor como Messiaen, nem sempre transmitem o sentido de brevidade do haiku. A linguagem musical, fria e inexpressiva, sem lugar para o elemento surpresa, consiste em blocos estáticos de textura intricada e densa que levam o ouvinte a vivenciar complexidade em vez de simplicidade. A estrutura tradicional do haiku, com seu modelo de três linhas cada uma com 5, 7, e 5 sílabas, tampouco tem consequência nas peças de Messiaen, embora este fato encontre um precedente na escola de poetas japoneses Soun, que praticava uma forma livre de haikai curtos (STRYK, 1981). Apesar das sempre presentes transcrições de cantos de pássaros, a ligação com a natureza permanece inaccessivel, exceto àqueles ouvintes capazes de reconhecê-las como cantos de pássaros, ou àqueles que tem um conhecimento prévio do amor de Messiaen pela natureza. De fato, os seus processos composicionais, ou melhor, a escrita musical de Messiaen (écriture) ${ }^{1}$ e sua estética musical são incompatíveis com as características do haiku acima mencionadas.

\section{2 - Messiaen e a nostalgia}

Esta falta de conexão com a estética do haiku parece indicar que Messiaen nunca deixou realmente o seu próprio mundo - o da música europeia - e nunca deixou de estar centrado em si mesmo. Ou será que existe escondida uma intenção mais profunda? A maior parte dos escritos musicológicos sobre Sept Haikai raramente vão além de relatar a viagem de lua de mel como sendo a única inspiração e razão de Messiaen para compor esta música. A história parece nos dizer que os Sept Haikai nasceram claramente de um impulso nostálgico em que a cultura e estética de um Japão exótico e longínquo representam a condição sublimada e romantizada à qual Messiaen forte e saudosamente deseja retornar ou se conectar. $E$ esta conexão é apenas momentânea, como uma breve visita turística, quase acidental, pois Sept Haikai é a primeira e única referência ao Japão em toda a grande obra do compositor. Exceto, talvez, na ópera St. François d'Assise, no modo pelo qual o anjo se move: o movimento, baseado no lento caminhar do ator do teatro Nô, busca intencionalmente despertar no expectador a sensação de estranheza, de algo que não pertence a este mundo ${ }^{2}$.

Entretanto, um novo modo de compreender o inteiro grupo de sete haikai nos é dado pelo movimento central, intitulado Gagaku. Este é o haiku onde Messiaen transcende o impulso nostálgico e redime a sua inteira obra "japonesa". Messiaen consegue isto através da religião.

Em 1950, a carreira de Messiaen já tinha se estabelecido, solidamente firmada na tradição musical francesa e fortemente imbuída da teologia católica. Desde uma de suas primeiras obras orquestrais, Les Offrandes Oubliées, de 1930, Messiaen tencionava "levar a ideia da liturgia católica para fora dos edifícios de pedra para os quais este gênero de música tinha sido destinado" (PERIER, 1979). Ele colocou a sua música a serviço das verdades eternas da fé católica. Esta missão permeia sua inteira obra até sua última composição, exceto durante 0 intervalo de treze anos que poderia ser chamado de "os anos de vanguarda", que vão de 1949 a 1962, como se verá mais adiante.

Aos olhos tecnocráticos da vanguarda europeia do pósguerra - que na França das décadas de 1950 e 1960 se tornara a corrente prevalente de pensamento - Messiaen teria sido o compositor nostálgico par excellence, já que a visão de arte da vanguarda, com seu caráter cientista e anti-metafísico, não favorecia muito um assunto como a religião. 0 que poderia ser mais nostálgico do que a religião, que significa religar-se a Deus? 0 que poderia estar em maior contradição com o espírito positivista do ultra-modernismo? Como poderia não ser nostálgica a tentativa de religar-se a algo que estava morto desde a proclamação de Nietzsche a respeito de Deus? Para a vanguarda, nostalgia é uma forma de fraqueza, um impulso reacionário, que não impele o artista adiante em direção ao progresso e ao futuro, mas sim para trás, em direção a algo que a vanguarda considerava inalcançável e ilusório. 0 lugar de Messiaen na vanguarda mostra um exemplo único na dialética entre nostalgia e inovação. Como poderia um compositor de música teológica tornar-se aceito pela vanguarda ateia?

\section{3 - Messiaen e a vanguarda}

A abertura de Messiaen para com as tradições musicais não-europeias valeu-lhe a fama de excêntrico entre os acadêmicos do Conservatoire de Paris. Esta mesma abertura também fez com que ele se interessasse ativamente pelas ideias das novas gerações de compositores. Messiaen ensinou quase todos os mais importantes compositores de vanguarda nascidos na década de 1920 e tornou-se o mais prestigioso professor de composição da Europa desde 1942 até um pouco depois de 1980. Os "anos de vanguarda" de Messiaen registram uma intensa troca com os compositores mais jovens e um interesse mais acentuado em novos métodos e técnicas de composição. Com a primeira execução de Réveil des Oiseaux no Festival de Donaueshingen de 1953, Messiaen tornou-se oficialmente um membro "senior" do movimento de vanguarda, como observou GRIFFITHS (1995).

0 período que vai de 1949 até 1962 poderia ser chamado de "os anos de vanguarda" do compositor, pois não existe no Messiaen deste período, uma dedicação exclusiva aos temas religiosos. ${ }^{3}$ De fato, nota-se uma preponderância de temas não religiosos nas composições a partir de Cantéyodjayâ e Quatre Études de Ritme (1949), e uma ênfase na música baseada em cantos de pássaros a partir de Le Merle Noire, de 1952. Certamente, durante os "anos de vanguarda" ele não abriu mão completamente da religião, pois a natureza e a ornitologia ainda pertencem, para Messiaen, ao âmbito da teologia. 0 significado místico dos pássaros como equivalentes na terra aos anjos do céu completam esta conexão. Couleurs de la Cité Céleste, de 1963, marca o retorno às composições 
de conteúdo católico. Esta é uma forte indicação de que, com a finalidade de permitir que ocorresse um ulterior progresso na sua escrita, os interesses religiosos de Messiaen tiveram que, temporariamente, abrir caminho para uma abordagem quase exclusivamente tecnológica, interessada em métodos composicionais novos e mais complexos baseados na sua pesquisa de ritmo e cor, e no canto de pássaros.

Graças a esta manobra tecnológica Messiaen estabeleceuse no movimento de vanguarda renovando sua criatividade e seu papel profissional como compositor. Seu próximo passo foi retornar à teologia católica, agora revigorado pela inovação composicional que o diálogo com a nova geração lhe inspirou e proporcionou. Na qualidade de bemamado professor de seus alunos e colegas vanguardistas, Messiaen gozou do raro privilégio de não sofrer ataques da parte deles por causa das tendências nostálgicas e dos conteúdos extra-musicais de sua obra.

Além dos pássaros, Gagaku é o elo perdido entre positivismo e teologia. Sept Haikai, de 1962, dos quais Gagaku é o quarto movimento, é a última composição dos "anos de vanguarda", e se coloca entre Chronochromie, de 1960 e Couleurs de la Cité Céleste, de 1963, que marca o retorno à teologia católica. Sept Haikai adota alguns dos materiais de Chronochromie e continua a exploração altamente complexa e sistemática de sua técnica envolvendo cores e durações (JOHNSON, 1975). Entretanto, os dois anos de pausa na atividade de composição que separam Chronochromie e Sept Haikai refletem um novo passo no caminho artístico de Messiaen e uma mudança importante na sua vida pessoal. A atmosfera deste novo momento composicional é o de um novo começo de vida, uma atitude mais relaxada concernente à composição, a intenção de re-usar novas descobertas em vez de buscar outras ainda mais novas, uma abertura a permitir-se gozar do "paraíso exótico" do Japão, e um retorno explícito à religião. Ainda que não se trate de uma peça religiosa, Sept Haikai mostra que a mente do compositor tinha se aberto a aceitar este outro paraíso com tal intensidade que ele decidiu homenageá-lo.

A obra contém, em Gagaku, uma revisitação da teologia num novo cenário, o do Xintoísmo, no lugar do Catolicismo, embora Messiaen tenha tratado de deixar bem claro, numa entrevista com Claude Samuel (SAMUEL, 1986), que ele "reproduziu a atmosfera estática, hierática e sagrada do gagaku enquanto, ao mesmo tempo, tentou dar a ela uma dimensão cristã". Tal observação demonstra quão importante era, para ele, não colocar em dúvida seu próprio catolicismo: ela renuncia qualquer possibilidade de identificação que Messiaen poderia ter pessoalmente com o xintoísmo, ao revelar uma atitude quase missionária, pois, "dar uma dimensão cristã" à atmosfera sagrada (xintoísta) do gagaku parece pretender "corrigi-la" de algum modo, e substituí-la pela única "fé verdadeira", a católica. Infelizmente não é mais possível perguntar ao compositor o que exatamente ele quis dizer com isto, ou como ele teria conferido esta dimensão cristã.
Uma tentativa de resposta a este como, porém, poderá ser abordada mais à frente, após a introdução da ideia de "transcrição estilizada". Por ora, é preciso considerar outras observações mais felizes de Messiaen, que provam a existência de alguma afinidade musical e estética que permitiu a aproximação destas duas religiões na obra de um compositor que não tinha a menor necessidade de associar-se a uma religião diferente da dele próprio.

\section{4 - Messiaen e o gagaku japonês}

Messiaen estava consciente da afinidade estética que liga a sua música com o gagaku japonês. Numa entrevista com Claude SAMUEL (1986) ele diz:

\begin{abstract}
"A música japonesa é estática, e eu sou um compositor estático porque acredito no invisível e no além; eu acredito na eternidade. Agora, os orientais estão em termos muito mais próximos com o além do que nós estamos, e é por isso que a música deles é estática. A música escrita por mim, um crente, é igualmente estática. Isto sem dúvida explica a minha atração pelo Japão."
\end{abstract}

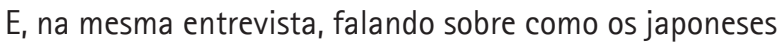
percebem a sua música, ele diz (SAMUEL, 1986):

\footnotetext{
"Eu acredito que os japoneses compreenderam o papel da cor na minha música, mas também - embora eles não sejam cristãos - o sentido de ritual, pois eles desenvolveram este sentido em si próprios através da prática do culto aos ancestrais... os japoneses vivem uma realidade febrilmente agitada, até mesmo descuidadamente perigosa, mas, ao mesmo tempo, eles cultivam a esfera do sagrado, do invisível, do estático.
}

Nestas palavras pessoais, informais e quase naïve, Messiaen dá a sua resposta pessoal à questão da dialética entre nostalgia e inovação. Como foi mencionado anteriormente, seu objetivo original era o de trazer a música litúrgica católica para dentro da sala de concerto. Graças à sua sólida compreensão da tradição do cantochão, acrescentada ao seu trabalho de organista na liturgia católica na igreja de La Sainte Trinité em Paris, Messiaen era profundamente imbuído do sentido de estase e ritual contidos na música sacra cristã. A esta experiência acrescentou-se a influência de Claude Debussy e Igor Stravinsky, e a linguagem musical de Messiaen tornouse fortemente não-dialética e estática. Nem toda a sua música é estática, mas, enquanto esta qualidade foi amadurecendo e encontrou novo impulso e expressão através dos seus "anos de vanguarda", ela se transformou numa característica do seu estilo até mesmo nas obras que não fazem referência teológica e que foram compostas por meio de considerações puramente estruturais.

De que modo a música transmite o senso de ritual e estase? Existe uma enorme discrepância entre os estilos do gagaku japonês e Gagaku de Messiaen. Mas, uma vez que se a ultrapassa é possível mesmo ouvir as semelhanças musicais entre os dois, tanto que já se viu nelas um ato de imitação (GRIFFITHS, 1995), e de "falsificação simpatizante" (WATKINS, 1995) ${ }^{4}$. Entretanto, considerando os procedimentos composicionais de Messiaen como um todo, é o conceito de transcrição estilizada, e não o de imitação, que realmente se aplica a 
este caso. A transcrição estilizada é uma marca registrada na escrita musical de Messiaen, como a exemplificam as suas transcrições orquestrais de cantos de pássaros ou de cantos gregorianos, a adoção de metros gregos e de células rítmicas (deçi-tâlas) do tratado musical de Śārngadeva, as transcrições destes ritmos e suas justaposições e sobreposições criando novas estruturas rítmicas, e a estilização dos sons do gamelan da Indonésia.

Em Gagaku, não há transcrição nota por nota, mas uma transcrição do papel de certos instrumentos no conjunto instrumental ou, em outras palavras, a transcrição da

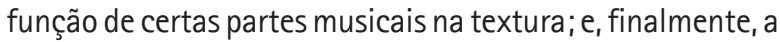
"transcrição" da atmosfera da música ritual japonesa. Estas partes musicais são, portanto, "re-escritas", transcritas/ assimiladas no/pelo estilo de Messiaen, resultando em melodias e harmonias completamente diferentes. Messiaen (MESSIAEN, 1966) escreve na partitura de Sept Haikai:

"Gagaku é a musica nobre do Japão do século VII, ainda praticada hoje pela corte imperial. Aqui aparecem os dois timbres principais desta música: o Sho (órgão de boca), substituido por um conjunto de oito violinos, e o Hichiriki (oboé primitivo), substituido pelo trompete."

Que o hitiriki seja um "oboé primitivo" é uma concepção comum, mas equivocada e eurocêntrica, baseada na ideia de que um processo evolucionário global encontra o seu ponto culminante na cultura ocidental. Ao mesmo tempo em que Messiaen compartilhou desta percepção ultrapassada, ele não deixou de perceber a alta sofisticação da música instrumental gagaku, especialmente a da categoria tōgaku, que se originou na dinastia Tang da China. 0 fato de que o órgão de boca syô é empregado apenas no conjunto tōgaku e não nos conjuntos das outras duas categorias de gagaku contemporâneo (TERAUCHI, 1998) indica que o interesse de Messiaen se voltou para a música tōgaku, embora ele não mencione este termo mais específico. As outras categorias são, a propósito, komagaku, de origem coreana, e o conjunto misto vocal e instrumental, mikagura, de origem autóctone japonesa.

Retomando a questão que ficou em aberto um pouco acima, sobre de que maneira Messiaen teria dado uma dimensão cristã à atmosfera sagrada do gagaku, é possivel especular que, talvez isto tenha sido feito através da transcrição estilizada, que teria emprestado ao modelo japonês uma vestimenta ocidental, a da técnica composicional e de orquestração do próprio Messiaen, que tinham estado já há tanto tempo associadas, em sua música, ao cristianismo. Messiaen teria, então, emprestado "o seu som" (católico) ao som do gagaku. Mas isto só foi possível porque o sentido de ritual e estase já estava presente em ambos.

\section{5 - Circularidade no gagaku japonês}

0 modelo de conjunto instrumental tōgaku para execução musical na corte e nas cerimônias dos templos combina sopros (três syô ou "órgãos de boca", três oboés hitiriki, três flautas ryûteki), cordas percutidas (dois biwa e dois koto), e instrumentos de percussão (um de cada dos seguintes: tambores kakko e taiko e o gongo syôko). 0 termo gagaku significa "musica elegante" (MALM, 1959). Eis, em seguida, uma breve descrição - baseada no mais famoso exemplo do repertório kangen ${ }^{5}$, a composição Etenraku (MARETT, 1990) - de como o gagaku japonês transmite estase e ritual.

A linha melódica é distribuída heterofonicamente em todos os instrumentos de sopro, com os syô provendo, com seus dezessete tubos de bambu, clusters ou blocos sonoros de cinco ou seis notas como acompanhamento. Esta harmonia tem uma função unicamente coloristica, e seu conteúdo intervalar é do tipo pentatônico.

A linha melódica básica é apresentada pelo hitiriki com inflexões microtonais e glissandi, enquanto o ryûteki provê uma sofisticada ornamentação. As unidades estruturais que a constituem repetem-se ao longo de toda a peça, e, embora possam ser reconheciveis como motivos que não se transformam, parecem flutuar em torno das mesmas notas, dando a sensação de uma invariância que, ao mesmo tempo, não permite a identificação do que é invariante. Não se forma um processo sonoro narrativo, que seria caracterizado por uma estrutura inicial, uma estrutura final, e as transformações contínuas que levam da primeira à última (STOIANOVA, 1976) ${ }^{6}$. As durações na melodia são moderadamente longas e parecem ser organicamente governadas pela respiração. 0 ouvinte percebe um ritmo melódico e uma pulsação elementares e fluidos mas solenes e, ao mesmo tempo, não tem tanto a sensação de ritmo no sentido tradicional do termo, mas sim uma sensação de durações.

Os arpejos periódicos dados pelos instrumentos de cordas percutidas produzem um acento agógico lento, da mesma maneira que os padrões rítmicos básicos do tambor kakko e os lentos golpes individuais no gongo syôko e no tambor grave taiko. Embora os tremoli do kakko comecem lentamente e se acelerem gradualmente, não há neles nenhum senso de transformação, gradual ou não. Os tremoli neste padrão lento/rápido se repetem sem produzir nenhum senso de direção ou mudança na agógica em geral.

Embora repetitiva, a música, considerando a textura em todos os seus componentes, nunca se repete de modo idêntico. A falta de mudança produz um efeito de tempo suspenso: a música é estática. Não há teleologia, nenhuma direção proposital num processo sonoro de transformação. Também não há desenvolvimento. 0 dinamismo que existe entre os componentes da textura - a linha principal e suas derivações heterofônicas, a harmonia/timbre dos syô, os acentos e tremoli da percussão - uma vez estabelecido, não se altera, e se prolonga durante toda a duração da música, sem que os componentes se alterem fundamentalmente ou troquem de função. Não existe clímax dramático.

Eu denomino este conjunto de características circularidade, pois a música produz a sensação de permanecer em torno 
de um estado de coisas ou clima sem começo nem fim, exceto por ter-se iniciado arbitrariamente, e terminado por simplesmente deixar de proceder adiante, cessando de continuar num ponto onde o ciclo - que de outro modo continuaria - parece permitir um senso de conclusão. Circularidade produz um falso movimento e, portanto, um movimento estático.

\section{6 - Circularidade no Gagaku de Messiaen}

0 único objetivo desta breve análise de Gagaku de Messiaen é o de demonstrar a circularidade dos processos composicionais, e de que modo ela realiza o sentido de estase e ritual. Portanto, não pretende ser uma análise exaustiva.

A peça tem quatro camadas de textura sobrepostas. $\mathrm{Na}$ primeira, a melodia principal é tocada pelo trompete, dobrado em uníssono por dois oboés e um corno inglês, correspondendo ao papel do hittiriki japonês. A segunda camada não tem um elemento correspondente no "modelo" japonês, embora Robert Sherlaw Johnson a tenha comparado com o papel do ryûteki (JOHNSON, 1975). A meu ver, a heterofonia do modelo japonês se perde na transcrição, quando Messiaen opta por uma polifonia entre as duas camadas. Esta segunda camada consiste em intervalos dissonantes de ritmo homofônico tocados pela flauta piccolo e por um clarinete em Mi bemol, em contraponto com a melodia principal da primeira camada. $\mathrm{Na}$ terceira camada, oito violinos recebem a tarefa de tocar harmonias "quase desagradáveis" (MESSIAEN, 1966), sul ponticello, sem vibrato, e forte. Isto corresponde à parte do órgão de boca syô, mas aqui os blocos sonoros pentatônicos se transformam em clusters cromáticos de oito sons diferentes. A quarta camada consiste numa polifonia a quatro vozes, cada uma designada a um percussionista. Três deles têm, cada um respectivamente, um conjunto diferente de metais cromáticos: sinos de vacas, crótalos, e carrilhão orquestral. 0 quarto percussionista toca sete instrumentos de metal: dois pratos turcos, dois gongos, um prato chinês, e dois tam-tams.

Do mesmo modo que os outros movimentos de Sept Haikai, Gagaku é um tempo circular, contido em si próprio, nãodramático, não-narrativo, não-teleológico e estático, comparável àquilo que Karlheinz Stockhausen cunhou de "moment form" (forma-momento) aplicado à sua própria música. Kramer considera Chronochromie, e Couleurs de la Cité Céleste, as duas composições adjacentes a Sept Haikai na cronologia das obras de Messiaen, como composições em forma-momento "praticamente puras" (KRAMER, 1988). Em seu todo, mas também em cada movimento isoladamente, Sept Haikai pode ser qualificado do mesmo modo, embora recaia na forma mais antiga de composição ou suite em vários movimentos.

A écriture de Messiaen constrói o tempo suspenso e estático de Gagaku através da sobreposição e coordenação de três camadas melódico-harmônicas de música num único bloco formado por três seções: $A$, com 4 compassos, B com 9 compassos, e $C$ com outros 9 compassos, no seguinte arranjo simétrico: $A B C A B$. Embora isto não crie uma unidade tão fechada em si mesma quanto um dos ritmos não-retrogradáveis típicos que Messiaen teria criado, tal como ABCBA, ainda assim, o arranjo gera um forte senso de fechamento. As repetições de $A$ e $B$ ocorrem de modo praticamente idêntico, diferenciando-se apenas por detalhes de ornamentação. As seções não se distinguem claramente ao ouvido. A distinção que existe entre as seções na melodia principal é como que "embaçada" pelo uso de motivos muito similares uns aos outros irregularmente justapostos, de modo muito semelhante à linha principal de Etenraku (Exemplo 1). A melodia flutua em volta dos mesmos tons, Fa\# e Sol\# no registro mais baixo, e Re e Mi (ou Do\#) no registro mais alto.

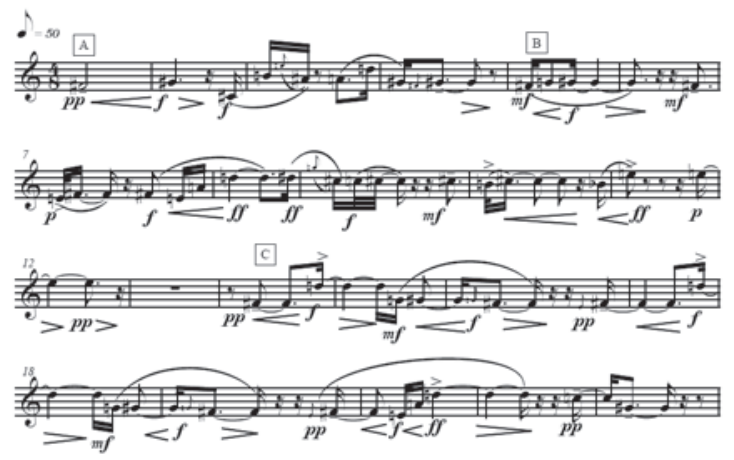

Ex.1 - Linha melódica principal de Gagaku.

Com permissão de Alphonse Leduc et Cie., Paris, França.

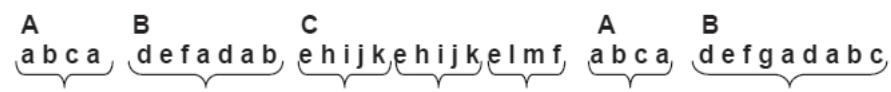

Ex.2 - Ordem dos acordes/cores de Gagaku. 
0 modo como os acordes da camada dos violinos se seguem uns aos outros também está a serviço da não-linearidade e da não-progressão (exemplo 2). Existem treze diferentes acordes/clusters/cores pré-fabricados, que representei nesse exemplo pelas letras minúsculas de "a" a "m". Como eles também se articulam em três seções paralelamente à camada melódica na disposição $A B C A B$ mencionada acima, o resultado é uma consecução de acordes/cores, harmonias/timbres errantes, que não tem senso de direção.

Note-se que a repetição de $A$ é idêntica, enquanto que a de $B$ é quase idêntica, contendo apenas a inserção do acorde " $g$ " entre "f" e "a" e sua finalização com o acorde "c". Quanto a C, unidade central, constitui-se de duas ocorrências da sequência "e- $h-i-j-k "$ seguidas de uma diferente, "e-I-m-f".

Estes acordes "pairam" acima da melodia "como o céu está acima da terra", no dizer dos japoneses, conforme observa Messiaen (SAMUEL, 1986).

A camada da percussão é bastante complexa em si mesma. 0 compositor atribui a cada um dos três conjuntos de instrumentos cromáticos de metal um diferente ciclo de permutação de durações que vão, cada uma, de uma fusa a trinta fusas. Estes ciclos são as permutações nos. 19, 20 e 21 da tábua de trinta e seis ciclos de permutações de durações que Messiaen criou para Chronochromie. A parte do quarto percussionista difere das outras três tanto estruturalmente como em dinâmica, pois não se utiliza das permutações de durações em fusas adicionadas e tem uma intensidade piano, enquanto as partes dos outros três estão em pianissimo. A quarta parte consiste em tocar os sete instrumentos em sete notas sempre na mesma ordem (dois pratos turcos, seguidos por dois gongos, prato chinês, dois tam-tams) cinco vezes, porém, com ligeiras irregularidades ao longo da parte, e sempre com um modo ligeiramente diferente de retardar o ritmo a cada vez.

Devido à sobreposição das camadas melódicas, de harmonias/timbres e de percussão, a textura das três primeiras linhas de percussão não chega a se separar da quarta linha do mesmo modo como se destacaria se o ouvinte pudesse escutar apenas a percussão, isolada das melodias. A percepção desta polifonia a quatro partes de sonâncias metálicas é de tipo global. 0 ouvido as integra num campo estatístico de klangs e reverberações, como uma massa sonora de sinos ao longe. Trata-se, portanto, de um fenômeno tímbrico, semelhante ao fenômeno dos oito violinos. A combinação dos instrumentos melódicos e de percussão é uma música continuamente errante dentro da sua própria esfera de movimento ou falso-movimento.

Enquanto a música de Messiaen tinha pouca ligação com a estética do haiku, ela estava bastante próxima dos princípios centrais do gagaku. Isto consiste no senso de estase e ritual transmitido por ambas as formas musicais, a japonesa e a do compositor francês. Quanto aos outros movimentos de Sept Haikai, eles também são todos estáticos, mas somente Gagaku é "hierático, estático, às vezes religioso e nostálgico, com um andamento lento e implacável", conforme MESSIAEN (1966) descreve o caráter geral da peça na partitura.

Cabe perguntar: por que os outros movimentos não transmitem o mesmo senso de ritual que Gagaku transmite, apesar deles também serem compostos na mesma linguagem musical estática, repetitiva e nãodramática? Talvez seja apenas por causa da força da sugestão no título, trazendo a imagem de ritual à mente do ouvinte. Talvez seja por causa do andamento lento e do sentimento de procissão produzido por ritmos lentos e simples, e pelo fato de que, em Gagaku, o ouvinte sente uma pulsação que, nos outros movimentos não é tão perceptível. Talvez seja uma consequência da transcrição estilizada, que, de modo indeterminado, consegue transpor o devir solene do ritual do modelo japonês.

Seja por que for, a forma-momento, a circularidade, e a não-teleologia produzem em música a vivência de menos movimento, tornando-a mais próxima de algo que se coloca fora do tempo, algo absoluto a priori do tempo do mundo dos fenômenos, o "além", conforme Messiaen colocou. Mas a música é fenômeno e tempo, e só pode "fingir" que não é..., ou melhor, só pode produzir um símbolo daquilo que está fora do tempo. Quando a música expressa fixidez e falta de movimento, ela está mais próxima da ideia de eternidade, e carrega nossa imaginação para fora do mundo do devir e dos fenômenos relativos. A tendência espiritual - enquanto oposta à tendência materialista, mecanicista e intelectual -, a vivência do Sagrado, é expressa em música pela estase produzida por uma linguagem musical circular e não narrativa.

\section{7 - Conclusão}

Vimos como a existência, no nível da estética, de um elemento comum entre o gagaku japonês e o Gagaku de Messiaen garantiu a condição necessária para a transformação de um impulso inicialmente nostálgico em um impulso inovador. Este elemento comum é o senso de estase e de ritual, presente no gagaku e já presente, independente e anteriormente, na música de Messiaen. Sem este elemento, Messiaen nunca teria superado o impulso nostálgico.

Vimos também que os elementos superficiais, estilísticos - mais especificamente, os materiais musicais e os papéis funcionais das partes instrumentais, mas também a linguagem de alturas, as durações, a textura - do gagaku passaram por um processo de transcrição que imediatamente os transformou em elementos estilísticos de Messiaen, aquilo que chamei de transcrição estilizada. 0 efeito de "semelhança" com o gagaku japonês ficou onipresente, mas difícil de se apontar com precisão. 
Portanto, além daquele elemento estético comum, surge a escrita de Messiaen desempenhando um papel decisivo e ativo nesta transformação de nostalgia em inovação. Ativo porque nela reside o poder do conhecimento e dos meios materiais para a concretização: o uso de técnicas já enumeradas acima - de manipulação destes signos da escrita, uso consciente dos resultados que elas produzem. A escrita age aqui como um filtro, transformando os materiais japoneses do passado nos materiais "do futuro" ou, melhor dizendo, da vanguarda, impedindo que eles tivessem sido simplesmente imitados ou copiados.

Esta relação não-imitativa da composição Gagaku com o "modelo" japonês cancela todo desejo de "tornar-se japonês" - que, de fato, Messiaen parece nunca ter tido - ou de retornar ao passado. Tais desejos teriam somente fixado o nostálgico e incorreriam numa perda de autenticidade artística e de comportamento. É esta não-imitação que faz de Gagaku uma peça tipicamente francesa ou, num sentido mais amplo, europeia. Dizendo isto, não pretendo aqui individuar o que há de francês na composição ou no estilo de Messiaen, mesmo porque, neste período, a composição europeia era um fenômeno internacional mais do que nacional, onde compositores franceses, alemães, belgas, italianos, trocavam ideias, técnicas, filosofias. Além disso, a aproximação ao elemento japonês vem a complicar ainda mais a possibilidade de identificar o que ali poderia ser francês. De maior interesse é reconhecer como a nostalgia se transformou no novo. Trata-se de reconhecer que foi o artifício da escrita, o modus operandi do compositor europeu - enquanto criação de sons musicais através da escrita de signos que representam sons - que constituiu, no caso do Gagaku de Messiaen, o elemento formativo responsável por esta transformação. Isto transformou 0 seu impulso inicialmente nostálgico numa contribuição inovadora para a música ocidental.

A mesma atitude se repete no que diz respeito à religião. Messiaen, um compositor profundamente católico, viu no gagaku japonês uma expressão do sagrado. Por um momento, ele se permitiu visitar o universo da religião xintoísta, mas não houve nenhuma conversão ou influência japonesa. Messiaen permaneceu em sua própria fé e foi capaz de perceber e reconhecer um elemento comum, a profunda similaridade, e talvez identidade, do sagrado da sua religião com o sagrado do Japão tradicional.

\section{Referências:}

DUFOURT, Hughes. Musique, pouvoir, écriture. Paris: Christian Bourgois Éditeur, 1991. Tradução italiana: Musica, potere, scrittura. Lucca, BMG Ricordi S.p.A., 1997.

JOHNSON, Robert Sherlaw. Messiaen. Berkeley e Los Angeles: University of California Press, 1975.

KRAMER, Jonathan. The Time of Music. New York: Schirmer Books, 1988.

MALM, William P. Japanese Music and Musical Instruments. Rutland, Vermont \& Tokyo: Charles E.Tuttle Company Publishers, 1959.

MARETT, Allan. Gagaku. Notas do CD Japanese Traditional Music - GAGAKU (Kunaicho-Gakubu) Gravação Tokyo: KING RECORD 1990.

MESSIAEN, Olivier. Technique of my Musical Language. Translated by John Satterfield. Paris: Alphonse Leduc, 1956. Sept Haikai. Paris: Alphonse Leduc, 1966.

Traité de Rythme, de Couleur, et d'Ornithologie. Paris: Alphonse Leduc, 1994.

PERIER, Alain. Messiaen. Paris: Editions du Seuil, 1979.

SAMUEL, Claude. Olivier Messiaen: Music and Color. Conversations with Claude Samuel. Portland, Oregon: Amadeus Press, 1986.

STOIANOVA, Ivanka. "Narrativisme, Teleologie et Invariance dans I'Oeuvre Musicale a propos de Rituel de Pierre Boulez". Musique en Jeu 25 (November 1976): 18-31.

STRYK, Lucien, Takashi Ikemoto. The Penguin Book of Zen Poetry. Londres: Penguin Books, 1981.

TERAUCHI, Naoko. "Gagaku". The Garland Encyclopaedia of World Music, v.7. East Asia: China, Japan, and Korea. Robert C. Provine, Yosihiko Tokumaru, and J. Lawrence Witzleben, editores. New York: Garland Pub., 1998.

WATKINS, Glenn. Pyramids at the Louvre:Music, Culture, and Collage from Stravinsky to the Postmodernists. , Massachusetts: The Belknap Press of Harvard University Press, 1995. 


\section{Notas}

10 termo écriture, muito usado na França, e igualmente na Itália (scrittura), refere-se à escrita musical do compositor. Embora também em uso na língua portuguesa, o termo escrita não é usado em música, no Brasil, tão frequentemente quanto em literatura e, nos meios musicais brasileiros, não parece ter o mesmo peso que tem nas línguas francesa ou italiana. Mantenho o uso do termo em francês neste artigo não por preciosismo, nem por simplesmente querer honrar o fato de Messiaen ser um compositor francês, mas porque o termo écriture conota enfaticamente a escolha tecnológica e racionalista da cultura europeia, que submete o ouvido ao olho, e reúne em si vários aspectos da criação musical ocidental, que vão desde a notação e as técnicas de manipulação dos signos que formam o texto musical à estética e filosofia que lhe dão suporte, passando também pelo estilo. De fato, a escrita musical do compositor não se resume à caligrafia, nem à notação musical, nem tampouco aos processos composicionais ou à sua linguagem musical. Trata-se do conjunto de atitudes, princípios e procedimentos criativos e formativos de que se serve o compositor no processo poiético, abrangendo a notação, as técnicas, os procedimentos de estruturação, a estética, a linguagem, as associações interdisciplinares e inter-artísticas. A escrita tampouco se resume no estilo. Este é um resultado da escrita; através do estudo do estilo podem-se acessar alguns elementos da escrita de um compositor. Para uma história e filosofia da escrita na música europeia ver DUFOURT, 1991.

2 Este ponto referente à movimentação do anjo me foi trazido por Christopher Dingle, especialista em Messiaen, em conversa pessoal durante o simpósio no qual apresentei este artigo.

3 As únicas composições teológicas do periodo de 1949 a 1962 são Messe de la Pentecoste (1949), Verset pour la fête de la Dedicáce (1960), e Livre d'orgue, (1951-1952), todas para órgão solo. Esta última reúne peças de uso litúrgico, mas que estão escritas numa linguagem mais "abstrata" do que a das outras duas.

4 "...e ele simpatizando com a música japonesa, falsificou um ensemble de corte Gagaku em fila com um catalogue des oiseaux miniatura no seu Sept Haikai de 1962" (WATKINS, 1995) (minha tradução).

5 Kangen é o repertório tōgakuquando executado sem dança.

6 Stoianova chama as estrutura inicial e final de "entidades" (STOIANOVA, 1976).

Luigi Antonio Irlandini é professor adjunto no Departamento de Música da UDESC, onde leciona harmonia, contraponto, análise e composição. Estudou composição com Hans-Joachim Koellreutter no Brasil, Franco Donatoni na Itália, e Brian Ferneyhough nos Estados Unidos. Obteve mestrado e doutorado em composição, respectivamente, no California Institute of the Arts, e na University of California (UCSB). Irlandini foi lecturer em composição e música do século XX na UCSB e cursou pós-doutorado em composição e música eletrônica junto ao CREATE, Center for Electronic Art and Technology na mesma universidade. Suas composições têm sido executadas no Brasil, Estados Unidos, Itália, Holanda, Japão e Argentina. Irlandini escreveu o artigo Gagaku, de Olivier Messiaen, originalmente em inglês, e apresentou-o no simpósio Nostalgia \&t Innovation in Twentieth-Century French Music, da Royal Music Association, no Lancaster Institute for the Contemporary Arts da Lancaster University, Inglaterra, em 9 de Maio de 2009. 